\title{
Respiratory rate - interobserver reliability study
}

\author{
Jacob B Brodersen ${ }^{1,2^{*}}$, Peter Hallas ${ }^{3}$, Mikkel Brabrand ${ }^{2,4}$ \\ From 6th Danish Emergency Medicine Conference \\ Odense, Denmark. 20-21 November 2014
}

\section{Background}

Measuring respiratory rate (RR) is one of the most basic clinical observations performed when accessing acutely ill patients. RR is included in most triage systems and risk stratifications tools, but unlike the other vital signs, $R R$ is typically obtained by a manual count by the nursing staff. Considering how often RR is used in clinical practice and contained in triage systems, it is remarkable how few studies on inter-observer/rater agreement have actually been performed. Furthermore, the existing studies are all made with few observers and many patients, and none of them have been performed in an actual acute setting of an emergency department (ED). We therefore aimed to determine the interobserver variability of $R R$ counts, using a larger number of observers on few same patients in the setting of an ED.

\section{Methods}

This is a reliability study on the manual count of RR, based on video recordings made at the admission of acutely ill medical patients to the emergency department. The assessment of RR was done as a part of a larger triage study, making the raters unaware of the focus on RR. The main study was a cross-sectional study on the reliability of existing triage systems. The videos were recorded during the first 15 minutes after arrival of the patient to the Emergency Department at Sydvestjysk Sygehus, Esbjerg. The videos were anonymized and shown as part of the complete internet-based questionnaire. We calculated the individual Intra Class Coefficient.

\section{Results}

Seven patient videos were assessed by eight observers. Each observer only assessed one case. All observers were trained nurses with a median experience of 15.23

\footnotetext{
* Correspondence: jbbrodersen@dadlnet.dk

'Department of Medical Gastroenterology, OUH Odense University Hospital, Odense, Denmark

Full list of author information is available at the end of the article
}

years (range $0-37$ ). The assessment of $R R$ of each video ranged from 22-36, 24-32, 14-32, 12-30, 22-32, 20-30 and 19-30, respectively. The individual absolute ICC was 0.13 (95\% confidence interval: 0.00-0.56).

\section{Conclusions}

We found poor agreement comparing the actual number of breaths per minute and a very low ICC. However, our methods of using video recording in the ED on acutely ill patients as a base for inter-observer studies proved useful, and have potential for further use.

\section{Authors' details}

'Department of Medical Gastroenterology, OUH Odense University Hospital, Odense, Denmark. ${ }^{2}$ Department of Emergency Medicine, Sydvestjysk Sygehus, Esbjerg, Denmark. ${ }^{3}$ Copenhagen University Hospital, Department of Pediatric Anesthesia, Rigshospitalet, Copenhagen, Denmark. ${ }^{4}$ Department of Emergency Medicine, OUH Odense University Hospital, Odense, Denmark.

Published: 16 July 2015

doi:10.1186/1757-7241-23-S1-A14

Cite this article as: Brodersen et al:: Respiratory rate - interobserver reliability study. Scandinavian Journal of Trauma, Resuscitation and Emergency Medicine 2015 23(Suppl 1):A14.

Submit your next manuscript to BioMed Central and take full advantage of:

- Convenient online submission

- Thorough peer review

- No space constraints or color figure charges

- Immediate publication on acceptance

- Inclusion in PubMed, CAS, Scopus and Google Scholar

- Research which is freely available for redistribution

Submit your manuscript at www.biomedcentral.com/submit

\section{( Biomed Central}

() Biomed Central

(c) 2015 Brodersen et al. This is an Open Access article distributed under the terms of the Creative Commons Attribution License (http://creativecommons.org/licenses/by/4.0), which permits unrestricted use, distribution, and reproduction in any medium, provided the original work is properly cited. The Creative Commons Public Domain Dedication waiver (http://creativecommons.org/ publicdomain/zero/1.0/) applies to the data made available in this article, unless otherwise stated. 